\title{
Integrated Education Management System via Cloud Computing
}

\author{
https://doi.org/10.3991/ijim.v11i2.6560 \\ Samir Abou El-Seoud \\ The British University in Egypt (BUE), Cairo, Egypt \\ Eslam Abo Gamie ${ }^{*}$ \\ The British University in Egypt (BUE), Cairo, Egypt \\ eslam.gamiedbue.edu.eg \\ Mostafa Salama \\ The British University in Egypt (BUE), Cairo, Egypt
}

\begin{abstract}
In this work, we present a framework to integrate the functionalities of the Enterprise Resource Planning (ERP) with the University academic and management functionalities at the British University in Egypt, in order to produce a University Resource Planning (URP) that facilitates the integration between educational and management processes within higher educational institutions.

Our ERP systems should be enabled to:

- Automate admissions. Eliminate manual processes and save significant staff time by enabling prospective students to apply online through a self-service portal. Provide one-stop student access. Allow students to enroll, register, and pay for courses through the portal.

- Simplify records management. With a single system for all your data needs - and a single digital record for each student — any department on campus can find the student information they need.

- Engage faculty. Give faculty the means to enter and update grades, and have personalized access to timely, accurate, and institution-wide information.

- Manage resources. Manage personnel, funds and processes more transparently.

- Strengthen decision-making. Track the metrics you need to guide day-today operations, meet reporting requirements, and engage your organization.
\end{abstract}

Keywords-Integrated management systems for higher education, eLearning, MOODLE, cloud technology, systems integrity.

\section{Introduction}

Systems integrity is one of the most important - yet complicated topics in Higher education domain. The demand for improved and integrated digital campus had been increasing dramatically during the last decade; that is why educational technology 
professionals continue to think more critically about how their students, academics, processes and technology can work together homogeneously.

Enterprise Resource Planning (ERP) can definitely guarantee processes integrity from various departments, which can be defined as "Software applications that organize, define and standardize the business processes necessary to effectively plan and control an organization".

ERP can be defined as a system that helps organizations manage their financials, supply chain, manufacturing, operations, reporting, and human resources. Most ERP systems can be deployed on-premises or in the cloud, to improve and automate the core parts of your business.

With the right enterprise resource planning software, all your business processes come together for easy collaboration and rapid decision-making to enhance your team's overall productivity. Leverage integrated systems for:

- Financial management: Gain control over your assets, cash flow, and accounting.

- Supply chain and operations management: Streamline your purchasing, manufacturing, inventory, and sales order processing.

- Customer relationship management: Improve customer service, and increase cross-sell and upsell opportunities.

- Project management: Get what you need to deliver work on time and on budget with better billing and project monitoring.

- Human resources management: Get help attracting and retaining good employees with tools to help hire, manage, and pay your team.

- Business intelligence: Make smart decisions with easy-to-use reporting, analysis, and business intelligence tools.

With default functional areas of ERPs are financial accounting, Human resource management, Manufacturing, order Processing, supply chain management, project management and customer relationship. However, to apply ERP for Higher education more work should be done before integrity concerns are incorporated systematically into the everyday operation higher education. Increased reflection and exchange are required on how to best re-design traditional regulatory management and control mechanisms so that they become more "integrity sensitive"; and on how to build on them with new accountability approaches or strategies that have proven successful [1].

The rapid expansion in universities' academic and management departments requires vast and flexible infrastructure solutions, virtualization and cloud computing can assure such flexibility, cloud computing can be defined as "means storing and accessing data and programs over the Internet instead of your computer's hard drive. The cloud is just a metaphor for the Internet [2].

Cloud technology has many advantages including [3].

- cost efficient

- on demand service

- almost unlimited storage

- easy access to information 
- broad network access

- resource pooling

- quick deployment

- rapid elasticity and

- Measured service.

Cloud Computing technology is a recent development, and allows users to share data, software and other resources across multiple computers on the Internet. This is cost effective and can save time, space, and licensing fees. In Cloud Computing, it is difficult to maintain data integrity because the user usually has no control over the security mechanisms that are used to protect his/her data.

The British University in Egypt suffers from lack of systems integrity, for instance the eLeanring, the eLibray and Students record system (SRS) are working efficiently but as isolated islands. As evidence, the students still have to enroll themselves manually in their eLearning modules even after submitting their registration card on the SRS, leading to inaccurate records within each course.

The British University relies heavily on the cloud technology, giving flexibility to create, update and delete virtual resources; indeed such technology will be vital to deploy the ERP system without worrying about hardware and network configurations now or in the near future.

With ERP system, we would gain a community where students get the services they demand, faculty facilitate teaching and learning in the classroom or online and departmental staff have the information and support to be more effective.

\section{Overview of BUE electronic systems}

As mentioned before the BUE relies heavily on five main systems: The Learning Management System (LMS) based on MOODLE, eLibrary based on the popular open source KOHA, the Students Record System SRS, Finance System and finally the Human resource management system HRM (see Fig. 1). Below are the main core functionalities of each system:

1. Learning Management System (LMS): is a web based application contains all what a student need to facilitate and engage the learning process between $\mathrm{him} / \mathrm{her}$ with the instructors. LMS is a software application for the administration, documentation, tracking, reporting and delivery of electronic educational technology courses or training programs [4]. Main functionalities include course search, assignments creation and submission, lectures upload in different formats, online quizzes including automatic grading and student's grade book (online quizzes include different question types) and finally discussion forums which can also be used as a notification and announcement tool.

2. eLibrary: a web application for providing students with all books info and core library functionalities to the real BUE physical library. Main functionalities are book search in the library database by either author, publisher and/or book title, E-books, E-borrowing and finally prestigious journals subscription. 
3. Students' Record System: in house developed web application and considered as a vital system containing admission, student's programme, study timetable, final grades, attendance, personal data and Exams timetable module.

4. Finance System: a Microsoft licensed system for managing students' fees, staff salaries, purchases and revenues.Human Resource Management: for managing human resource department operations including leave requests, attendance reports, and update leave status and leave requests report.

BUE Digital Systems

\begin{tabular}{|c|c|c|c|c|}
\hline & elibrary & SRS & Finance & \\
\hline $\begin{array}{l}\text { - Course search } \\
\text { - Assignments } \\
\text { - Lectures } \\
\text { - Quizzes } \\
\text { - Notifications }\end{array}$ & $\begin{array}{l}\text { - Book search } \\
\text { - Online } \\
\text { databases } \\
\text { - E-books } \\
\text { - E-journals } \\
\text { - Borrowing }\end{array}$ & $\begin{array}{l}\text { - Admission } \\
\text { - Programme } \\
\text { - Study schedule } \\
\text { - Final Grades } \\
\text { - Attendance } \\
\text { - Personal data } \\
\text { - Exams schedule } \\
\text { - Personal tutor } \\
\text { - Modules evalua }\end{array}$ & $\begin{array}{l}\text { - Student fees } \\
\text { - Staff salaries } \\
\text { - Purchases } \\
\text { - Revenues } \\
\text { ation }\end{array}$ & $\begin{array}{l}\text { - Leave requests } \\
\text { - Attendance } \\
\text { report } \\
\text { - Update Leave } \\
\text { status } \\
\text { - Leave request } \\
\text { reports }\end{array}$ \\
\hline
\end{tabular}

Fig. 1. BUE Digital Systems

\section{Current systems workflow/communication}

The user starts the workflow by applying to the students' record system through the admission module; from which the SRS sends applicant data to the finance system, the applicant has to go the finance department to complete his/her financial process; finance replies back with approval. At this point the applicant is turned into an active student and further electronic accounts and ID cards are created. SRS can now send students data to the eLibrary (see Fig. 2).

With the beginning of each semester the Learning Management System (LMS) administrator starts creating courses and assigning teachers' role via the LMS, so the teacher starts managing his/her course contents and students will be able to enroll themselves in courses and start interacting with their course contents.

Faculty administrators send academic info to the SRS, SRS replies back with academic login credentials, to login to insert academic records like grades and attendance. Faculty administrator s send employees personalized data (part timers/full timers), preferred working hours to the Human Resource Management System (HRM). Finally, academics can check/manage their personalized data. 


\section{Systems Workflow}

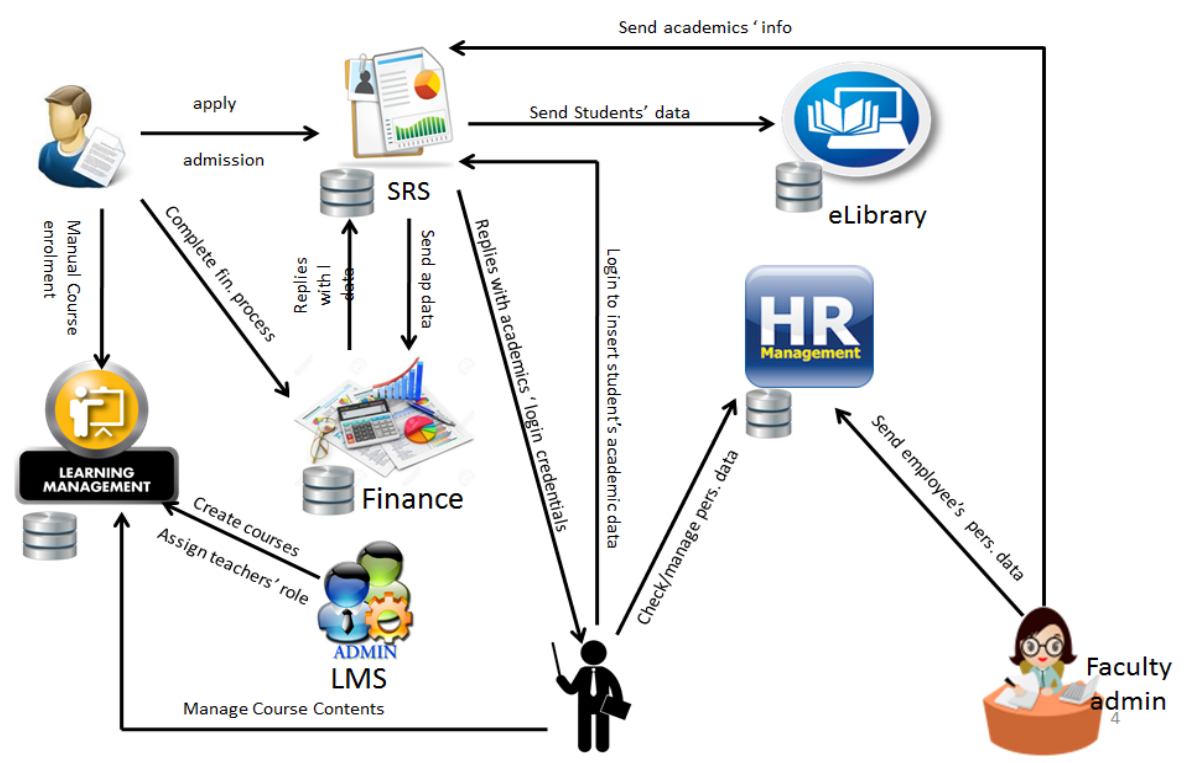

Fig. 2. Systems Workflow

\section{$4 \quad$ Improvement directions}

It is clear that the workflow is quite long, exhausting and complicated and further directions are required for improvement. Improvement directions are:

- Process Simplification: rather than having a long complicated process.

- Unified Process/Data: rather than redundant data and processes.

- Consistent User Interfaces: instead of interacting with variable user interfaces.

- Time Reduction: the current workflow is quite time exhaustive and complicated

- Centralization: scattered data and process may cause a lot of redundancy and time, that is why data centralization will be an optimum solution in this case

- Unified Systems Platform

\section{Proposed ERP based enhancement}

The basic idea behind enhancing the workflow is Enterprise Resource Planning (ERP), which is simply business process management software that allows organization to use a system of integrated modules to manage the business and automate many back office functions (see Fig. 3). Central feature of any ERP system is a very large shared database that supports multiple functions used by different business units. At the top of the database there is a data access control that monitors the access of different modules to different data.[8] 


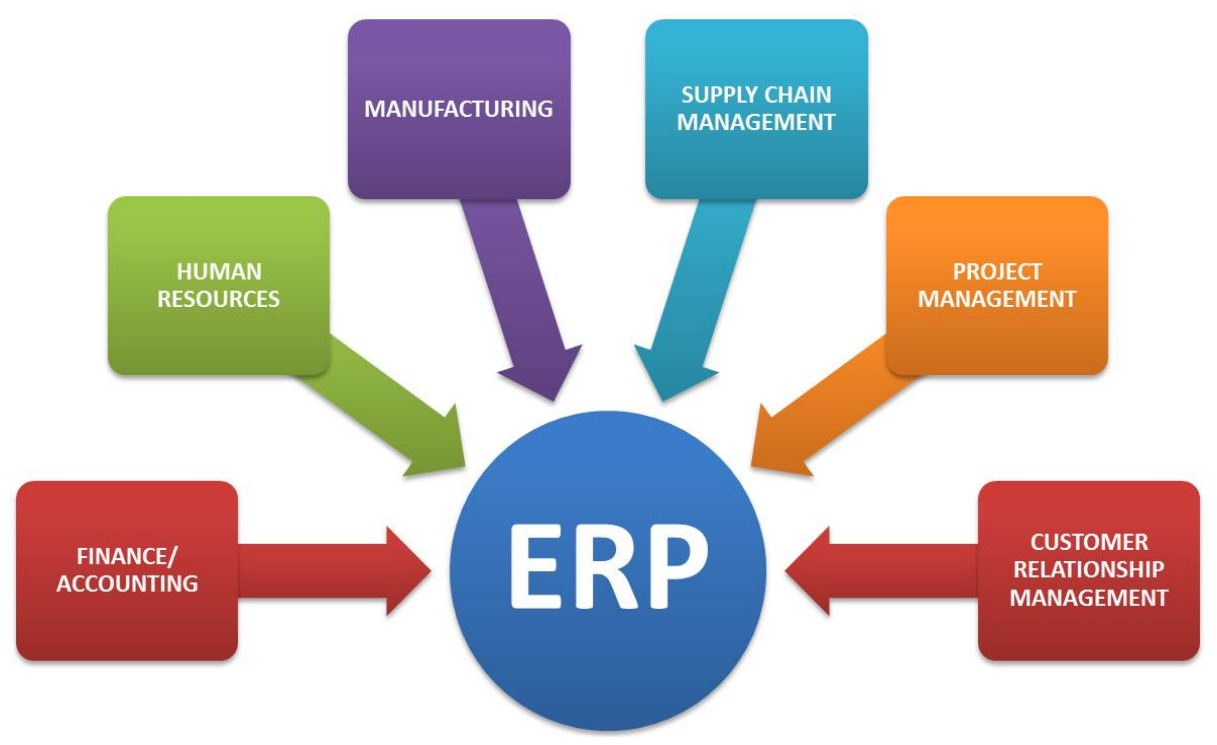

Fig. 3. Workflow Enhancement via ERP

\section{BUE systems workflow after enhancement}

Various users will start interacting with a consistent user interface based on the selected functionality. On the top of the large database there should exist a management control layer that will process the data from another components. For instance, the SRS has the right to know the status of students' payment and not his financial records. The data will be injected only once in the database and will reside whenever it is needed. For example, the Learning Management system could ask for the courses for each users to be enrolled, which can simply be retrieved from the shared database contacting the proper data that was already inserted by the Student Record System (see Fig. 4).

\section{$7 \quad$ Benefits}

By applying the enhancement directions to the current workflow, the main benefits are:

- Automated Workflow: reduce manual processes and save a lot of time by enabling students to apply online through a self-service user interface.

- Improved Information Access: Allow students to enrol, register, and pay for courses through the unified interface.

- Improved Services for faculty, students and employees: With a single system for all, and a single digital record for each student any department on campus can reach student's data when needed. 
- Strengthen decision-making: by analyzing day to day operations

- Reduce Administrative work

- Simplify Data Analysis and Reporting

- Scalability: in the future any other system could be integrated in the ERP in the form of a module

- Reduce mailing and paper work

- Reduce time

\section{Enhanced Workflow}

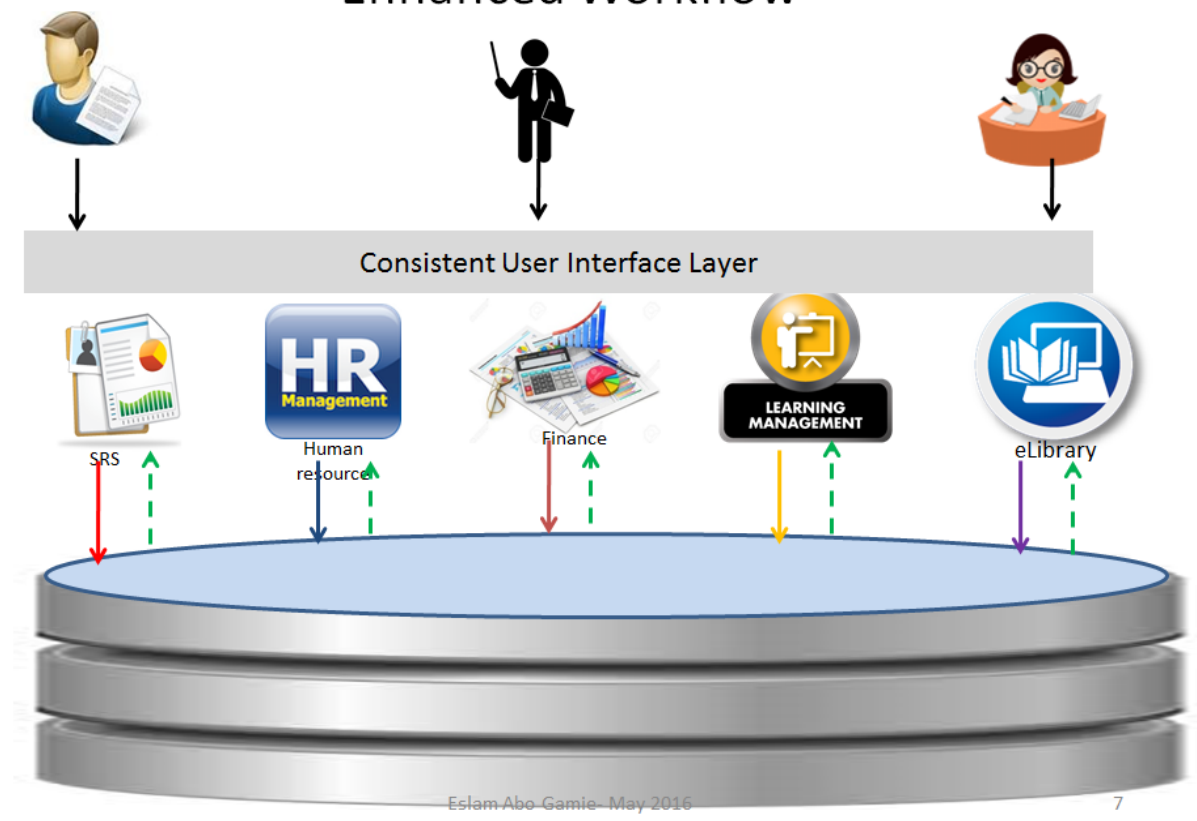

Fig. 4. Enhanced Workflow

\section{ERP vendors for higher education:}

Oracle, SCT, PeopleSoft, SAP, Jenzabar and Datatel are considered main ERP vendors for higher education.[7] According to Gartner Group the vendors are classified into: "leaders": visionary about future business activities, "challengers": reputable market position but with no future business visions and "visionaries": with a very good vision but with bad presence business operations, so there is no ideal solution for data decentralization at the British University in Egypt.

A drawback in most of ERP cloud providers is the data access problem, vendors will provide the whole solution as a service "online software" with no direct access to our data, leading to inflexible direct data management and a probability of data violation. 
With access to Microsoft cloud, in house implementation could be an optimum solution, with a direct access to all of the university data a full flexibility, taking into consideration PAAS "platform as service" as a main Cloud property

\section{System Implementation via Cloud:}

When it comes to implementation, cloud technology is always an option, for more than 4 years now, the British University has been utilizing Microsoft cloud technology as a platform as a service (PAAS) where the provider supports tools, methods and operating systems required to build a specific application. Deploying an open source (Moodle) on the cloud is not a difficult task; simply the developer chooses the specifications of the virtual machines (rams, cores, storage, etc ...) from Windows azure interface then the operating system and database type. For the Integrated Education Management system, implementation will be quite complex, each of the University's systems will convert into a module derived from the ERP framework, provided when needed.

SAP and Oracle provide a lot of cloud services SAAS per module and those modules are mainly for the enterprise solutions and not for educational institutions and considered relatively expensive.

The proposed system architecture will consume a virtual machine per module, plus an extra virtual machine; for the data access management within the British University in Egypt cloud network

The real challenge is to convert university systems into homogenous fully/semi connected modules, where a virtual set of resources from the cloud provider will be handling data access/management between them.

Each of the modules will represent a flow of real time institutional process, like a human resource transaction, eLearning transaction, eLibrary transaction, etc...

Implementation phases:

1. Setting up virtual machines with suitable technical specifications

2. choosing the platform as service

3. installing operating systems

4. configuring databases and communication protocols between virtual machines

5. installing tools required for building/ conversion of modules

6. writing the conversion scripts and interfaces on the cloud

\section{Extended ERP features for Higher education:}

Business Intelligence (BI) plays a main role in the current ERP solutions, from which decisions makers could utilize such features to insight future decisions, for example a supermarket can suggest promotions tailored for a certain customers based on his purchases history, or to predict what item a certain client will purchase. The same concept can work in the higher education domain for the sake of predicting students' performance, Web usage mining is applied on the systems like Moodle e- 
learning for predicting the students' final marks. Such mining process is called Educational Data Mining (EDM) from which the explored knowledge could be analyzed to make critical decisions to enhance the learning process. The aim of the mining process is to discover the relation between the on-line activities of the student and his final marks. The frequent student-behavioral patterns are utilized in listing a set of rules about the reason of the success or the failure of students. Several researches are presented to define the problems that prevents the accurate generations of these and set approaching are proposed to solve these problems. The work in [5] works on the data imbalance problem that students who fail a subject are usually less than those who succeeded. The work in [6] deals with variance of the courses types and number of activities; it detects the relationship between activities and resources in the course and results obtained by the students.

Such feature can be added as an ERP module for higher education on a separate virtual machine to help academics and administrators to support their future missions and plans.

\section{Conclusion}

To sum up, the ERP system could be a solution for the current systems workflow problems facing the BUE. Centralization is the main concept behind the enhancement directions mentioned before. ERP is applied to a lot of business institutions but still in its early stages for academic institutions. With a very strong believe that ERP for higher education will be a vital in the near future to centralize, share, reduce time and cost.

As we mentioned before, BUE relies heavily on the cloud technology, giving flexibility to create, update and delete virtual resources. Indeed such technology will be vital to deploy the ERP system without worrying about hardware and network configurations now or in the near future.

\section{References}

[1] https://www.microsoft.com/en-us/Dynamics/what-is-erp.aspx

[2] http://me.pcmag.com/networking-communications-softwareproducts/1758/feature/what-is-cloud-computing

[3] http://mobiledevices.about.com/od/additionalresources/a/Cloud-Computing-Is-ItReally-All-That-Beneficial.htm

[4] https://en.wikipedia.org/wiki/Learning management system

[5] Romero, C., Romero, J.R., Luna, J.M., Ventura, S.: Mining rare association rules from e-learning data. In: Baker, R.S.J.D., Merceron, A., Pavlik Jr., P.I. (eds.) Proceedings of 3rd International Conference on Educational Data Mining, International Educational Data Mining Society, Pittsburgh, 2010, pp. 171-180

[6] Amelia Zafra and Sebastián Ventura, Predicting Student Grades in Learning Management Systems with Multiple Instance Genetic Programming. Proceedings 
Paper-Integrated Education Management System via Cloud Computing

of the 2nd International Conference on Educational Data Mining, Cordoba, Spain, July 1-3, 2009, pp. 307-314.

[7] Leo Zornada MSc., Tamara Bertok Velkavrh, 27th Int. Conf. Information Technology Interfaces ITI 2005, June 20-23, 2005, Cavtat, Croatia Implementing ERP Systems in Higher Education Institutions

[8] Raja Mohd Tariqi B. Raja Lope Ahmad, Zalinda Othman and Muriati Mukhtar,ieee

\section{Authors}

Samir ABOU EL-SEOUD, Eslam ABO GAMIE*, and Mostafa SALAMA are with The British University in Egypt (BUE), El Sherouk City Misr-Ismalia Road, Cairo, Egypt (eslam.gamie@bue.edu.eg).

This article is a revised version of a paper presented at the BUE International Conference on Sustainable Vital Technologies in Engineering and Informatics, held Nov 07, 2016 - Nov 09, 2016 , in Cairo, Egypt. Article submitted 21 December 2016. Published as resubmitted by the authors 17 January 2017. 